\title{
A Model of Literature Adoption in Higher Education: An Approach Using Historical Novels
}

\author{
Francisco Rejón-Guardia ${ }^{1} \&$ Andrés Palma-Valenzuela ${ }^{2}$ \\ ${ }^{1}$ Department of Business \& Economics, University of Balearic Islands, Spain \\ 2 Departamento de didáctica de las Ciencias Sociales, University of Granada, Spain \\ Correspondence: Francisco Rejón-Guardia, Assistant professor, Department of Business \& Economics, University of \\ Balearic Islands, Spain.
}

Received: January 17, 2017

Accepted: February 4, 2017

Online Published: March 7, 2017

doi:10.5430/irhe.v2n1p67

URL: https://doi.org/10.5430/irhe.v2n1p67

\begin{abstract}
This article outlines an innovative teaching project based on methodology, evaluation and skills acquisition through the educational use of the historical novel in higher education. A Computer-Assisted Web Interviewing (CAWI) was administered to 119 students. The data obtained allowed the development of a structural equation model using PLS (Partial Least Squares) to evaluate the major relationships between variables. This study expands the framework of analysis by using measurement scales from the perspective of the Advanced Research Model of Innovation Adoption (AMIA). The analysis results in a behavioural model using robust and parsimonious hypotheses supporting the research questions raised, highlighting the appropriate use of extended AMIA models. The use of this genre is an opportunity to learn interesting facts, past situations autonomously and has a great potential of novelty that involves the active participation and learning process of students, breaking down time and space barriers and creating informal learning.
\end{abstract}

Keywords: historical novel, innovation adoption, TAM, AMIA, pedagogical innovation

\section{Introduction}

This paper describes the use and analysis of a project of educational innovation from the aspects of methodology, assessment and acquisition of competencies, implemented within the framework of university education through the educational use of the historical novel. The objective is to assess, in as far as such a literary subgenre allows and from a constructivist approach, the improvement in the level of learning, the achievement of certain competencies and the increase of student involvement in the process of self-learning. Its originality lies in both the application of an advanced model of acceptance of innovation, which incorporates the most commonly used variables of models applied by previous theory, as well as its aim of responding to certain needs of teachers of the European Higher Education Area (EHEA). Special consideration is given to the interest of the novel as an educational resource, and to the acquisition of competencies directed towards shaping and evaluating the experience of its use as applied to the teaching and learning of the social sciences included in the university curriculum of teacher training for primary education. To this end, the historical novel has been taken as a reference for the theoretical-practical teaching of certain subjects in the area of social science during two semesters, in collaboration with various prestigious literary authors who provided ad hoc texts, with the conviction that this represented an opportunity to improve the process of teaching and learning the social sciences. With a view to assessing the impact of the implementation of this initiative, an experiment was carried out consisting of the evaluation of beliefs, attitudes and behaviours prior to the use of the novels in class, compared with the results obtained after the use of these texts in the classroom.

This paper is organised as follows: firstly, a literature review of the processing of the proposed model of acceptance of innovation is presented, highlighting those variables used in other models of acceptance. Next, on the basis of the framework proposed, the hypotheses and research proposals are described. Finally, the results and main conclusions are presented, along with their practical and theoretical implications, as well as the limitations of the study and recommended future lines of research.

\subsection{Framework}

This initiative stems from the conviction that current university curricula need to incorporate innovative, more 
dynamic teaching methodologies through which the students should acquire more prominence; this requires alternative and more effective ways of increasing their motivation. In this sense, we believe that the role of the teacher is to stimulate the student to reach the highest degree of involvement possible, as required by the new educational models (Batanero \& María, 2010). To meet this challenge, and as a response to this demand, a proposal was designed by the department of social sciences of the Faculty of Education at the University of Granada (Spain), geared towards the improvement of the teaching process. To this end, the use of the historical novel and historical short story was considered as applied educational resources, certain of their effectiveness in the development of experiences of quality learning, and for the students to be more effective in attaining the competencies set out in the curricula. The proposal was established as an innovative teaching project for academic years 2015-16 and 2016-17, entitled "The historical novel as an educational resource applied to the teaching-learning process in the area of social science" It was positively assessed by the National Agency for the Evaluation of Teaching Quality of the Ministry of Education, and approved in September 2015. Proposals were formulated for assignments adapted to various subjects in the teaching area of the social sciences, with the aim of improving the level of development of their objectives and competencies by means of activities pairing the binomials "education-literature" and "creativity-imagination". The development of activities was directed towards overcoming the difficulties detected in the teaching of an historical period, geographical space and the perception and comprehension of the anthropological and patrimonial reality of the environment. In the phase previous to the development of the project, an analysis was undertaken which demonstrated the existence of certain significant deficiencies: quantitative-qualitative deterioration in the quality of knowledge of social science; shortcomings in the teaching-learning process of history, geography and heritage; disturbing political and ideological factors; difficulties in understanding certain historical periods and realities; limitations in the proficiency of linguistic and cultural competencies; and problems with the production of written texts.

In the development stage, two issues caused concern: the system does not transmit the perception of temporality and spatiality; nor the construction of an effective historical awareness to enable students to locate and understand the historic dimensions of reality. It is therefore necessary for teachers training at the university to be made aware of these objectives when teaching the social sciences.

This situation is exacerbated by the verification that, firstly, in primary and secondary education there is little interest in studying these subjects, which are considered boring and unrelated to real life. Secondly, there is a lack of proficiency in linguistic and communicative skills, which prevent students from reaching the objectives established, despite having been included in the system since 2006. Thirdly, these deficiencies are a burden for academic activity. In response to this, an innovative use of the historical novel is offered with a view to optimizing the teaching of the current curricula, with the coordinated incorporation of the binomials "education-literature" and "creativity-imagination" into the teaching process in order to overcome the aforementioned difficulties within the teaching of the social sciences.

\subsection{Objectives and Activities}

In conjunction with the general objective proposed, two specific aims were established: to facilitate the teachers' professional work and to develop active and motivating processes with the students, connected to relevant areas of their educational training.

Objectives for the students:

Involve them in the learning process using methodologies that stimulate their participation and broaden their knowledge; improve their vocabulary; expose them to customs and values different from their own; develop historical memory; gain knowledge of and respect for the environment and patrimony; and have a better understanding of the present from knowledge of the past.

1) Involve students in the learning process through the educational use of literature.

2) Motivate them through reflexive reading and individual analysis, collaborative work and teacher support.

3) Foster their capacity to analyse, criticize, debate, and receive feedback on their work, both individually and in groups, following criteria of quality and promote relationships between students, teachers, writers and other professionals.

4) Encourage the use of other languages as auxiliary languages.

5) Improve their communicative capacity to transmit ideas.

6) Boost linguistic, social, civic, historical, cultural and artistic competencies, illustrated by the four skills of 
reading seeing, reflecting and questioning, in order to overcome the current deficit in humanist culture.

The aims related to the teaching staff were as follows:

1) To optimize coordination and efficiency in the development of their subjects from the aspects of sequencing and revitalization of part of their contents and competencies.

2) To identify the contribution of each subject to the competencies that the student must attain, and of the contents to be included.

3) To learn how to select literary texts to encourage the process of active learning and establish a link with the educational, linguistic and cultural environment.

4) To select and sequence educational resources appropriate for each case, together with the most suitable means and formats for their dissemination and final evaluation.

Perhaps the greatest interest of this proposal lies in its potential to implement an all-round/comprehensive education inculcating values as a way to improve certain deficiencies currently detected in the world of education. Activities carried out by the students:

1) Selection of the setting and the protagonists of the activity.

2) Timing: 15 weeks.

3) Students: 3 hours per week of theory in large groups and 2-3 seminars of 1 or 1.5 hours in small groups.

4) Individual work (checking sources, bibliography, group meetings).

5) Teachers' remote preparation: 6 hours of tutorials per week.

6) Module per course: 3 hours of taught theory and 2-3 seminars per group.

7) Total: 6 hours of theory and 9 hours of practice during one semester.

Stages of implementation:

1) presentation of the plan of activities: clarification of the criteria for action, objectives, methodology and direction of the process;

2) pathway of development: presentation of bibliography and material;

3) criteria for use of the material: libraries, digital platforms, etc.

4) specific rules for the reading of and working with literary material; texts for historical contextualization of the works; articles and essays introducing the texts as a literary reality and educational tool;

5) organization of the analytical work to be carried out on the chosen texts from four frames of reference: geographic-spatial, historical, anthropological and patrimonial at local, national and international level.

Methodology of practical sessions: students work prior to the session as indicated by the teacher on the specific bibliographic and literary material assigned. Active participation by the students through individual preparation and substantiated contributions. Study route followed through the setting and places of interest related to the text worked on. Appearances by the authors of the texts and other experts in front of the whole group. Closure of the practical seminars in a session attended by the whole student body and the authors, open to faculty teaching staff, using the following framework: introduction, speech by the author and debate with a panel of speakers. Preparation of a final report by each student on the activity carried out. This is assessed as part of the final process of evaluation of the subject.

\section{Literature Review}

The present study makes use of an AMIA model drawn from the variables proposed by Talukder (2014) but with the additional incorporation of variables suggested in other models of technological acceptance and innovation, as propounded by Frambach and Schillewaert (Talukder, 2014). A model of relationships was also tested in order to develop a more comprehensive model to investigate a wider range of factors that may affect individuals' adoption of innovation. In addition, the use of the AMIA model is based on the theory of reasoned action (TRA) (Fishbein, 1979), the technology acceptance model (TAM) (Davis, 1986), the conceptual framework provided by (Frambach and Schillewaert, 2002), the unified theory of acceptance and use of technology (UTAUT) (Ahmad, 2016), and DeLone and McLean's model of information systems (Delone \& McLean, 2003).

The first two categories of the model are behavioural and normative beliefs: individual factors and social influence. 
These behavioural factors are users' perceptions about innovation itself. The second category, social influence, describes these factors as individual perceptions which are affected by others, and are therefore normative beliefs. The third category includes organizational factors, or external factors. The external factors category is limited to factors within the organization where individuals work or in this case, study. These factors come from management policies, strategies and actions. These behavioural beliefs, normative beliefs, and external factors affect individual attitudes toward innovation, which consequently influence individuals' adoption of innovation. The link between attitude and adoption is well recognized and strongly supported in the literature (Lam, Cho, \& Qu, 2007). The proposed model retains behavioural intention as a stage between attitudes toward innovation and its adoption, as this allows the research to use the model to predict future intention to use an innovation. Under individual factors or behavioural beliefs, the AIMA model includes five variables: perceived usefulness, personal innovativeness, prior experience, image and enjoyment of innovation. Perceived usefulness is a well-recognized factor used by TAM and defined as "the degree to which an individual believes that using a particular innovation would enhance his or her job performance." (Davis, 1989). Personal innovativeness refers to an individual's willingness to use any innovation (Agarwal \& Prasad, 1998). Frambach \& Schillewaert (2002) define personal innovativeness as "the tendency of a person to accept an innovation within a product class, independent of the communicated experience of others". Image refers to the degree to which the use of innovation enhances one's image within an organization. This study has introduced an image variable into the advanced model, because it affects attitudes toward adoption. Enjoyment of innovation refers to the extent to which the activity of using innovation is perceived to be enjoyable and satisfies the individual. This study has used the term enjoyment of innovation as joy derived from the use of innovation which affects individuals' attitudes toward adoption. Social influence is a normative factor. Individuals are more likely to perform an act if they perceive the existence of greater social pressure from salient referents to perform that act. Frambach \& Schillewaert (2002) point out that "organizational members will exhibit more positive attitudes if people in their social environment also use focal innovation". The research also considers that normative beliefs are important in affecting individuals' behaviour toward adoption. Social influence is included in the advanced model as directly affecting individual attitude toward adoption. This refers to the extent to which members of a social network influence each other's behaviour, or employees are influenced by members in a similar discipline or other organizations outside of their own working environment. Frambach \& Schillewaert (2002) state that "when there is a critical mass of users within a person's reference or work group innovation usage by others in an individual's social environment is likely to play an important role in all types of innovations". Another important set of variables are organizational factors. In particular, Frambach \& Schillewaert, (2002) argued that external factors affect attitude and usage. The authors include organizational factors as external factors in their model and recommend they be tested in future research. They point out, for example, that these external influences affect an individual's awareness of the functioning and application of innovations and their fit with the job. There are three variables within organizational factors: training, managerial support and incentives. Training plays an important role in increasing user confidence in the ability to learn and use the innovation and encourages an individual to adopt innovation. Managerial support influences the use of innovation significantly, because users tend to innovate more if they believe adoption will be valued by management. Incentives refer to the individual's beliefs about the benefits or consequences of adoption of innovation (Cheung, Chang, \& Lai 2000). Previous studies have used behavioural intention in their models to explain adoption (Davis, 1989) and the findings imply that an effective use of innovation relies on positive intention toward adoption (Lam, Cho, \& Qu, 2007). The AMIA model uses the term "individual adoption" of innovation, as synonymous to individual acceptance, individual adoption, individual adoption decision, and use. This study has used the outline of the research model and then proposed an advanced research model of innovation adoption. The latter builds on the theory of reasoned actions and incorporates elements from the technology acceptance model, and at the same time introduces several modifications, the models, following on from the ideas of Frambach \& Schillewaert (2002). The results of this integrated study should identify actual adoption of innovation.

\section{Research Model and Hypotheses}

The model includes three categories of factors: individual factors, social influence, and organizational factors, which have the most significant influence on attitude and adoption. Within the three categories of factors there are eight independent variables: perceived usefulness; image; personal innovativeness; enjoyment of innovation; social influence; incentives; training; and managerial support. These variables affect attitude, which in turn influences individual adoption. The model retains behavioural intention as a surrogate, which allows the model to be used in predicting future intention. However, empirical study will investigate actual usage behaviour. Specifically, the following hypotheses are put forward based on the review of the theory (see Figure 1):

$\mathrm{H}_{1}=$ There is a direct positive relation between perceived usefulness and attitude toward innovation. 
$\mathrm{H}_{2}=$ The image variable has a direct positive influence on attitude toward innovation.

$\mathrm{H}_{3}=$ Innovativeness presents a direct and positive influence on attitude toward innovation.

$\mathrm{H}_{4}=$ the degree of enjoyment presents a direct and positive influence on attitude toward innovation.

$\mathrm{H}_{5}=$ Social influence affects directly and in a positive way attitude toward innovation.

$\mathrm{H}_{6}=$ Incentives influence directly and in a positive way attitude toward innovation.

$\mathrm{H}_{7}=$ Previous training presents a direct and positive relationship with attitude toward innovation.

$\mathrm{H}_{8}=$ Managerial support is positively and directly related to attitude toward innovation.

$\mathrm{H}_{9}=$ Attitude toward innovation has a positive and direct influence on behavioral intention.

$\mathrm{H}_{10}=$ Behavioral intention presents a direct and positive influence on individual adoption of innovation.

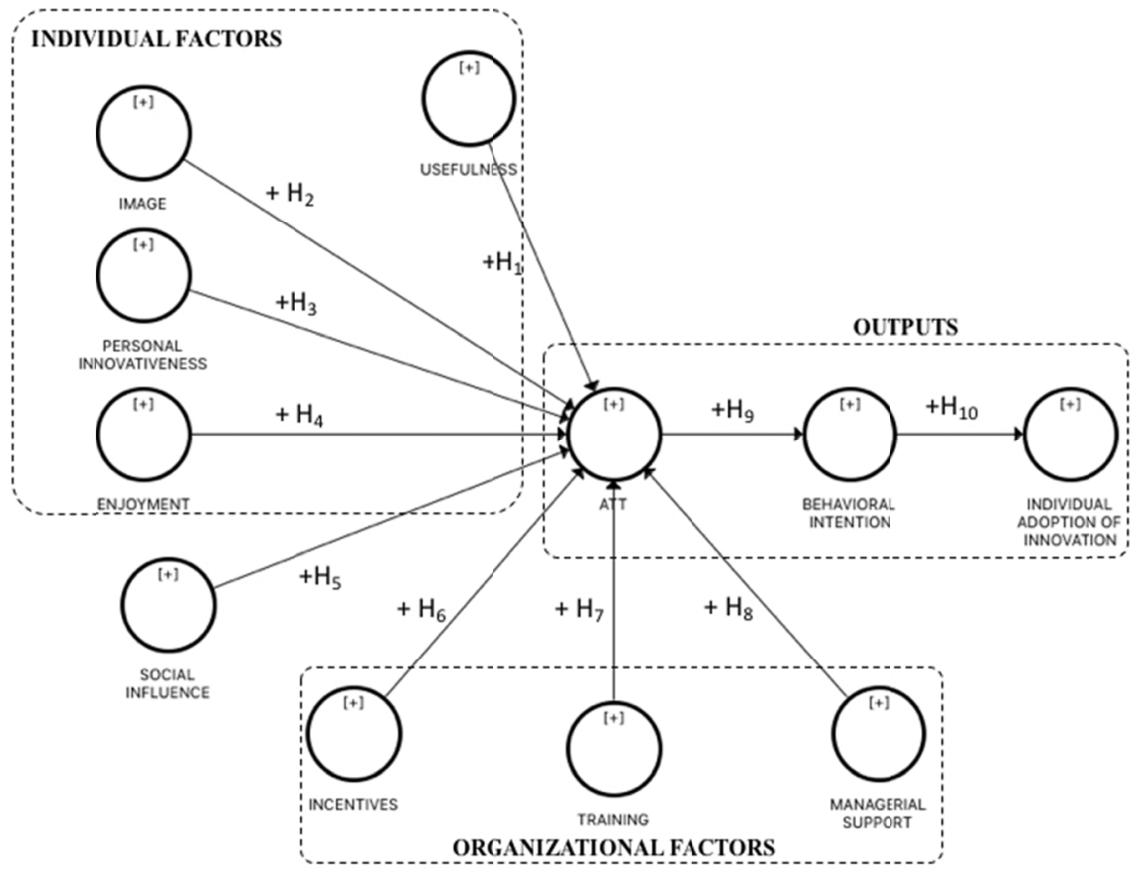

Figure 1. Proposed conceptual model of innovation adoption

\subsection{Research Methodology}

In order to assess the impact of the use of the historical novel, an experiment was carried out to evaluate beliefs, attitudes and behaviours prior to implementing the use of the novels in class, and compare these with the results after the use of the texts. In order to do so, the use of texts from historical novels was implemented during classes during two academic semesters, in collaboration with several reputed writers who contributed texts for educational use. In the quantitative approach the research used a literature review to identify questions and variables linked to a general causal explanation or interrelationship before collecting actual data. An online questionnaire was used as the primary quantitative data collection method. The questionnaire items had their origins in related studies and were empirically tested and validated in the context of innovation adoption. The instruments collected respondents' responses to various issues concerning the adoption and use of historical novels in learning activities. The questionnaire was based on a five-point Likert type scale: $1=$ strongly disagree to $7=$ strongly agree (see appendix, table 5 ). Statistical analysis was carried out using SPSS and SMARPLS in order to test the whole model.

Within this context and to evaluate the results, CAWI was used, including validated scales of the TAM (Talukder, 2014), widely used in higher education. However, these models have been widely criticized by academia for the simplicity of their assumptions and because their use is not appropriate when an innovation implies involuntary behaviours. In order to overcome this limitation, this research expands the analysis framework by using measurement scales from the perspective of the Advanced Research Model of Innovation Adoption (AMIA) (Frambach \& 
Schillewaert, 2002). In this case, variables and individual factors such as social influence, and attitudes toward innovation have been taken into consideration in order to predict an individual adoption of innovations. Finally, the moderating effects of some demographic variables (gender, age, regular reader) were also taken into account. The software used to record the online data was Typeform. The survey was sent out to students using historical novels between October 2015 and February 2016. The total data collection procedures took place during February and March 2016. A total of 119 completed questionnaires were received. The socio-demographic characteristics of the study sample are shown in Table 1 below.

Table 1. Socio-demographic characteristics

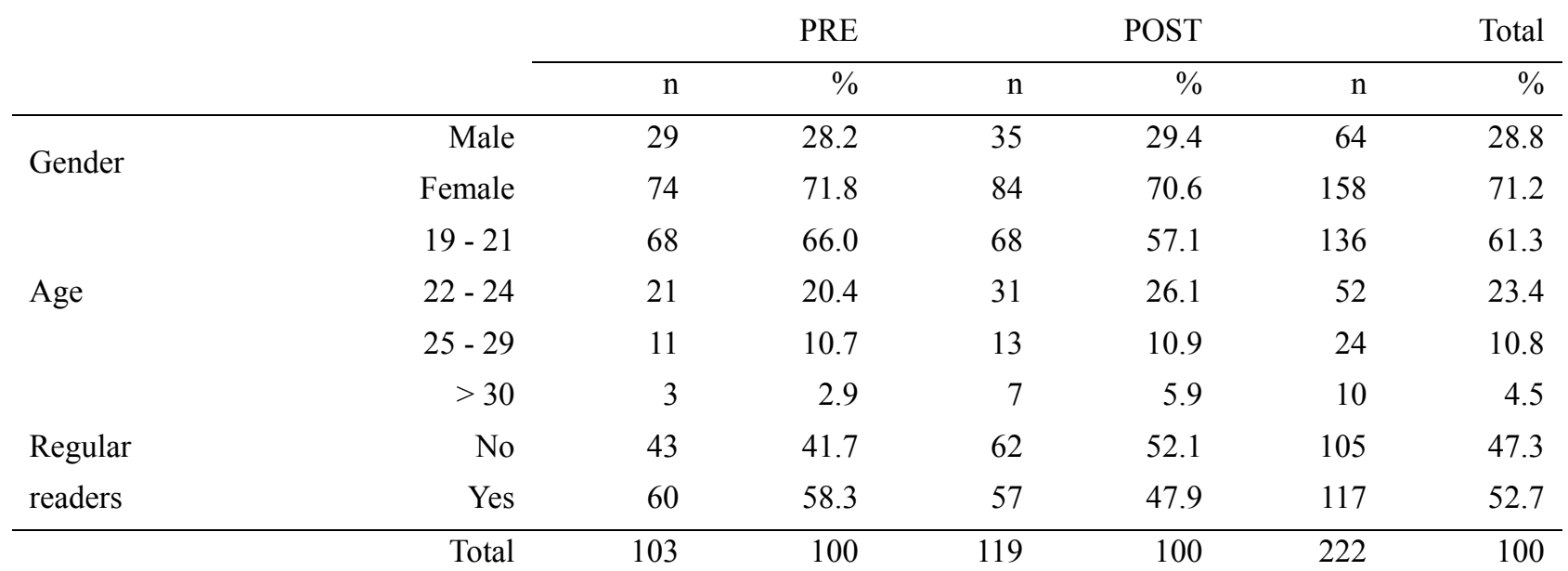

\subsection{Analysis and Results}

Table 2 shows the results of one-way ANOVAs pre- and post-class activities. The results demonstrate that the mean scores for "interesting" were significantly different between pre- $(\mathrm{M}=3.05, \mathrm{SD}=0.484)$ and post conditions $(\mathrm{M}=$ $3.24, \mathrm{SD}=0.596) ;(F(1,219)=6.113, p<.01)$. The mean scores for "use intention" were significantly different between pre- $(\mathrm{M}=4.64, \mathrm{SD}=1.565)$ and post conditions $(\mathrm{M}=5.11, \mathrm{SD}=1.339) ;(\mathrm{F}(1,219=5.978, \mathrm{p}<.01)$. In contrast, the mean scores for "improved knowledge of the course" were not significantly different between pre- $(\mathrm{M}=$ $5.40, \mathrm{SD}=1.338)$ and post class activities $(\mathrm{M}=5.38, \mathrm{SD}=1.262) ;(F(1,219)=.009, p=.924)$. Additionally, the mean score for "useful for learning" was not significantly different between pre- $(\mathrm{M}=5.36, \mathrm{SD}=1.312)$ and post class activities $(\mathrm{M}=5.38, \mathrm{SD}=1.262) ;(\mathrm{F}(1,219)=.016, \mathrm{p}=.899)$. The results indicate that the historical novel or short story was interesting for the students and that there were improvements in the intention to use them after the activities were carried out in class, compared with levels before doing the activities.

Table 2. Results of One-Way ANOVAs between pre and post class activities

Pre

$$
(\mathrm{n}=103)
$$

Post

$$
(\mathrm{n}=119)
$$

\begin{tabular}{ccccccc}
\hline & $\mathrm{M}$ & $\mathrm{SD}$ & $\mathrm{M}$ & $\mathrm{SD}$ & $\mathrm{F}$ & $\begin{array}{c}\mathrm{p} \\
\text { value }\end{array}$ \\
\cline { 2 - 7 } Interesting & 3.05 & 0.584 & 3.24 & 0.596 & 6.113 & .014 \\
Intention to use & 4.64 & 1.565 & 5.11 & 1.339 & 5.978 & .015 \\
$\begin{array}{c}\text { Improved knowledge } \\
\text { of the course }\end{array}$ & 5.40 & 1.338 & 5.38 & 1.262 & .009 & .924 \\
Useful for learning & 5.36 & 1.312 & 5.38 & 1.262 & .016 & .899 \\
\hline
\end{tabular}




\subsection{Results of the Structural Equation Model}

Table 3 shows the validation of the scales following the recommendations for reliability indices (Cronbach's alpha $>$ 0,8 , composite reliability $>0,8$, significant factor loadings) and validity of the scales (AVE > 0,5, HTMT, Fornell-Larcker) (Hair, Sarstedt, Hopkins, \& Kuppelwieser, 2014). Table 4 shows the results of the evaluation of the structural model and the analysis of the tests of hypothesis. The results obtained evidence an appropriate fit and predictive capacity of the model $\left(\mathrm{R}^{2}=0,603 ; \mathrm{Q}^{2}=0,411\right.$ (Chin, 1998; Stone, 1974); (SRMR =0,085 (Henseler \& Sarstedt, 2012). Furthermore, the size of the effect $\left(\mathrm{f}^{2}\right)$ reveals medium and high values, except in the case of usefulness on attitude toward innovation and social influence on attitude toward innovation, which allows us to affirm that the latent independent variables have a significant impact on the dependent variables.

Table 3. Evaluation of the measurement model: CR-composite reliability, AVE-extracted variance

\begin{tabular}{lrccr} 
Variables & $\begin{array}{r}\text { Cronbach's } \\
\text { Alpha }\end{array}$ & CR & AVE & Factor Loadings \\
\hline Usefulness & .930 & .950 & .827 & $.893-.923$ \\
Image & .859 & .913 & .778 & $.816-.917$ \\
Enjoyment & .889 & .931 & .819 & $.890-.914$ \\
Personal & .859 & .899 & .640 & $.754-.873$ \\
innovativeness & .831 & .898 & .747 & $.843-.902$ \\
Incentives & .786 & .863 & .616 & $.634-.889$ \\
Training & .951 & .965 & .872 & $.916-.959$ \\
Managerial support & .806 & .873 & .634 & $.647-.864$ \\
Social influence & .824 & .894 & .738 & $.773-.900$ \\
Attitude $\quad$ toward & .935 & .958 & .884 & $.935-.951$ \\
innovation inavioural intention & .879 & .912 & .675 & $.715-.875$ \\
Behavidual adoption of & & & & \\
Individu \\
innovation
\end{tabular}

With regard to the endogenous variables, usefulness, personal innovativeness and incentives can explain $60.3 \%$ of attitude toward innovation. The model explains $18.1 \%$ of behavioral intention and $28.3 \%$ of individual adoption of innovation. The strongest predictors of attitude toward innovation are personal innovativeness and incentives, followed by the direct and negative influence of intention of use.

Table 4. Evaluation of the model: correlation (R2), Stone-Geisser test (Q2), size of the effect (f2), composite reliability $(\mathrm{CR})$, extracted variance $(\mathrm{AVE})$, and factorial loads (bootstrapping $=5000)$

\begin{tabular}{|c|c|c|c|c|c|c|}
\hline \multicolumn{2}{|c|}{ Relationship constructs } & Path & $\mathrm{R}^{2}$ & $\mathrm{f}^{2}$ & $Q^{2}$ & SRMR \\
\hline H1 & Usefulness --> Attitude toward innovation & $-.329^{* * *}$ & & .076 n.s. & & \\
\hline $\mathrm{H} 2$ & Image --> Attitude toward innovation & -.050 n.s. & & .005 n.s. & & \\
\hline $\mathrm{H} 3$ & Innovativeness --> Attitude toward innovation & $.773^{* * *}$ & & $.765^{* * *}$ & & \\
\hline $\mathrm{H} 4$ & Enjoyment --> Attitude toward innovation & .011 n.s. & & .00 n.s. & & \\
\hline $\mathrm{H} 5$ & Social influence --> Attitude toward innovation & $.148^{*}$ & & .034 n.s. & & \\
\hline H6 & Incentives --> Attitude toward innovation & $.378^{* * *}$ & & $.130^{* *}$ & & \\
\hline $\mathrm{H} 7$ & Training --> Attitude toward innovation & -.050 n.s. & & .002 n.s. & & \\
\hline H8 & Managerial support --> Attitude toward innovation & -.095 n.s. & & $.00 \mathrm{n.s}$ & & \\
\hline H9 & Attitude toward innovation --> Behavioral intention & $.433^{* * *}$ & & $.408^{* * *}$ & & \\
\hline H10 & $\begin{array}{r}\text { Behavioral intention --> Individual adoption of } \\
\text { innovation }\end{array}$ & $.538^{* * *}$ & & $.408^{* * *}$ & & \\
\hline & Attitude toward innovation & & .603 & & .411 & \\
\hline & Behavioral intention & & .181 & & .161 & \\
\hline & Individual adoption of innovation & & .283 & & .189 & \\
\hline & SRMR Common Factor Model & & & & & .085 \\
\hline
\end{tabular}

Note. ${ }^{* * *} \mathrm{p}<0.001,{ }^{* *} \mathrm{p}<0.05,{ }^{*} \mathrm{p}<0.1$ 


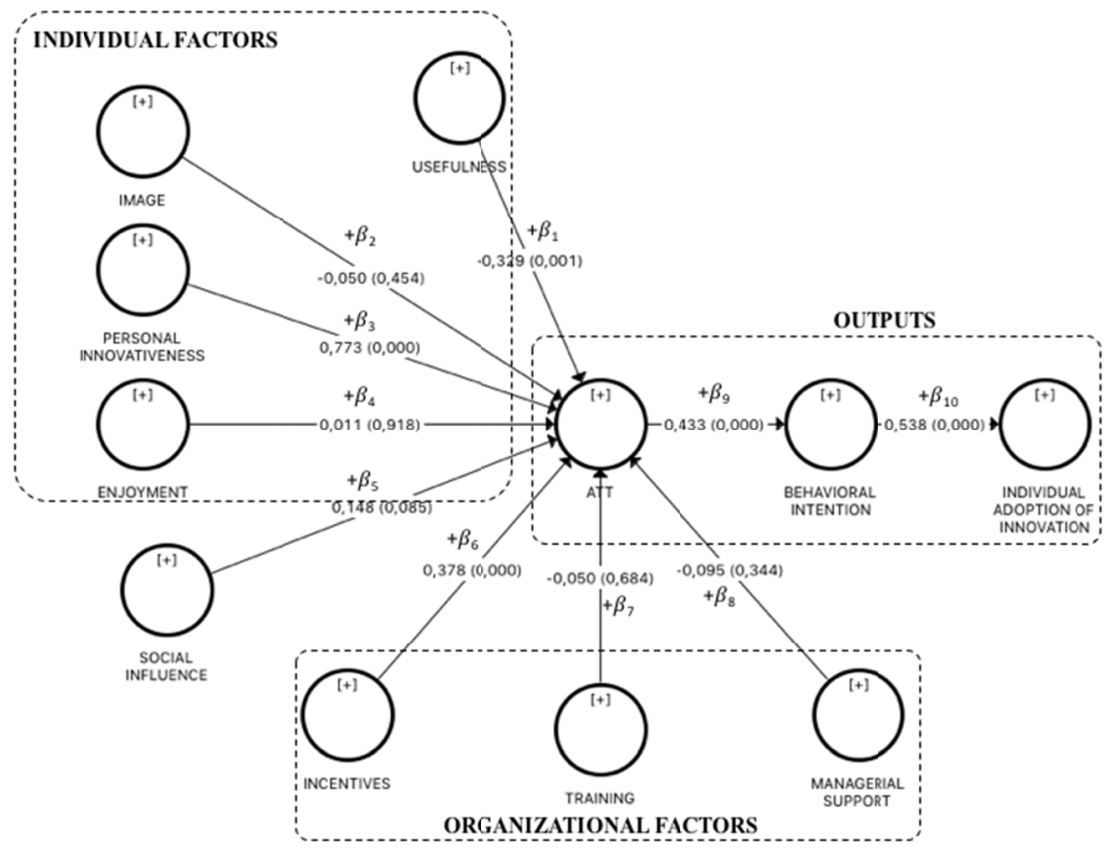

Figure 2. General Model - Final relationships

Figure 2 shows the results of the structural model. With regard to the hypotheses put forward about the individual factors affecting attitude toward innovation, the model did not corroborate the direct and positive influence of usefulness on attitude toward innovation $\left(\beta_{1}=-.329 ; \mathrm{p}<0,001\right)$, as the relationship established was negative. Consequently, the greater the ease of use detected, the lower the attitude toward innovation. The analysis revealed no direct and positive influence of image on attitude $\left(\beta_{2}=-.050 ; \mathrm{p}=.459\right)$, therefore, $\mathrm{H}_{2}$ was rejected. Conversely, the relationship proposed between personal innovativeness and attitude obtained sufficient empirical support to confirm a positive and strong relationship between these variables $\left(\beta_{3}=.773 ; \mathrm{p}<.001\right)$. The relationship between enjoyment and attitude was not corroborated $\left(\beta_{4}=.011 ; \mathrm{p}=.917\right)$, therefore, $\mathrm{H}_{4}$ was rejected. In the set of hypotheses related to social influence, hypothesis $\mathrm{H}_{5}$ proposed a direct and positive relationship between social influence and attitude, which was partially rejected for being $90 \%$ significant $\left(\beta_{5}=.148 ; \mathrm{p}<.1\right)$. For those hypotheses that promote an effect of organizational factors on attitude toward innovation, it can be observed that $\mathrm{H}_{6}$ obtained sufficient empirical support $\left(\beta_{6}=.378 ; \mathrm{p}<.001\right)$, affirming the relationship existing between incentives and attitude. However, hypothesis $\mathrm{H}_{7}$ was rejected $\left(\beta_{7}=-.050 ; \mathrm{p}=.683\right.$ ), as there was no existing relationship between training prior to the use of the innovation, and attitude, as with hypothesis $\mathrm{H}_{8}\left(\beta_{8}=-.095 ; \mathrm{p}=.341\right)$ which promoted the relationship between managerial support and attitude, but did not receive sufficient empirical support. Finally, hypothesis $\mathrm{H}_{9}$ was corroborated. A positive and direct relationship was established between attitude toward innovation and behavioral intention $\left(\beta_{9}=.433 ; \mathrm{p}<.001\right)$. Hypothesis $\mathrm{H}_{10}$ gained sufficient empirical support $\left(\beta_{10}=.538 ; \mathrm{p}<.001\right)$ confirming a relationship between behavioral intention and individual adoption of innovation.

\section{Conclusions}

The research assessed the influence of the use of the historical novel and short story as educational resources, by carrying out different activities with primary teachers in training. In particular, the influence of texts was assessed both before and after use, obtaining significant results in the intention of use and consideration of appropriateness. Thereafter, an advanced model of adoption of innovation was validated. This model was based on the theory of reasoned action (TRA) incorporating elements of the technology acceptance model (TAM) with additional modifications taken from Frambach \& Schillewaert (2002), and (Talukder, 2014). To this end, a questionnaire administered to different groups studying for a degree in primary education was analyzed using partial structural equations through SmartPLS software. The analysis revealed that the variable having the greatest impact on attitude toward innovation was personal innovativeness, followed by incentives. Specifically, the model explained $60.3 \%$ of attitude toward innovation. Therefore, the tendency of an individual to accept an innovation has a large influence on its intended use. For this reason, it is interesting to stimulate the curiosity of students and evaluate their propensity for innovation in order to guarantee the success of educational practices. If the innovation is believed to result in 
favourable outcomes for the individual, then the individual will be more likely to adopt it. As Currid (1995) proposes, incentives need not only be financial; outcomes that may be positively valued by individuals can be broadly conceived to include formal and informal recognition, increased autonomy, beliefs about self-worth and achievement. The finding that usefulness causes a negative and direct relationship on attitude toward innovation is contrary to support in previous literature upholding it as a positive relationship (Lewis, Agarwal, \& Sambamurthy, 2003). That high usefulness implies lower intention of use may be justified by the belief that more complex texts require a greater cognitive effort by the reader, and these more difficult texts are considered better a priori, and therefore of lower usefulness. Secondly, the precedent to behavioural intention was attitude toward innovation, where the relationship was significant and moderate. Thirdly, the principal antecedent of adoption of innovation was behavioral intention. This points clearly to the necessity to adapt the use of the modifications proposed by Talukder (2014) to an advanced model of acceptance of innovation, which could be used once the novel is adopted as a learning resource. The use of the historical novel has a great novelty potential that involves the active participation of students in the learning process, breaking down barriers of time and space and creating informal learning. It also involves a process of student self-management, which may indeed help the learning process. It may involve the students in achieving an improvement in their reading/writing skills as well as improving their vocabulary.

\section{Limitations and Future Research}

This contribution has certain limitations which should be the subject of debate and may open new lines of investigation. Firstly, with regard to the selected sample, only a group of students studying for a degree in primary education has been considered, which may distort the results and conclusions reached. For this reason, future studies should seek to expand the representativeness of the investigation by means of more varied and heterogeneous samples. The model of adoption has been used which is widely used with technological innovations. Hence some proposed relationships, which are amply supported in the literature, have resulted insignificant in this study. The conclusions and limitations identified point towards new lines of investigation. It is suggested that the study sample should be enlarged and software tools or applications be used in order to record the use of different texts. A detailed analysis of the literary texts should also be carried out to verify whether there are any differences between them in respect of attitudes, intentions and final behavior.

\section{Acknowledgements}

This work was supported by the University of Granada under Grand Number PID 15-22 (2015). We also benefited from comments on earlier versions of this paper given at the annual International Conference on Education and New Learning Technologies will be held in Barcelona (Spain).

\section{References}

Agarwal, R., \& Prasad, J. (1998). The antecedents and consequences of user perceptions in information technology adoption. Decision Support Systems, 22(1), 15-29. https://doi.org/10.1016/S0167-9236(97)00006-7

Ahmad, M. I. (2014). Unified Theory of Acceptance and Use of Technology (UTAUT). In proceedings of Fourth International Conference on ICT in our lives 2014 - Information Systems Supporting Decision Making" (ISSN 2314-8942), Information Systems and Computer Science Department, Faculty of Commerce, Alexandria University, Alexandria, Egypt, December 20-22.

Al-Gahtani, S. S., \& King, M. (1999). Attitudes, satisfaction and usage: factors contributing to each in the acceptance of information technology. Behaviour \& Information Technology, 18(4), 277-297. Retrieved from http://www.tandfonline.com/doi/abs/10.1080/014492999119020

Batanero, F., \& María, J. (2010). Obstacles or difficulties to the involvement and participation of «all» students in school activities. A study on the perception of teachers. Revista Internacional de Audición y Lenguaje, Logopedia y Apoyo a la Integración, 4(1), 1888-4857. Retrieved from https://idus.us.es/xmlui/handle/11441/24571

Cheung, W., Chang, M. K., \& Lai, V. S. (2000). Prediction of Internet and World Wide Web usage at work: a test of an extended Triandis model. Decision Support Systems, 30(1), 83-100. https://doi.org/10.1016/S0167-9236(00)00125-1

Chin, W. W. (1998). Commentary: Issues and Opinion on Structural Equation Modeling. MIS Quarterly, 22(1), vii-xvi. Retrieved from http://www.jstor.org/stable/249674

Currid, C. (1995). What to do when money does not motivate. Network World, 12(4), 52-54. 
Davis, F. D. (1986). A technology acceptance model for empirically testing new end-user information systems: Theory and results. Massachusetts Institute of Technology.

Davis, F. D. (1989). Perceived Usefulness, Perceived Ease of Use, and User Acceptance of Information Technology. MIS Quarterly, 13(3), 319-340.

Delone, W. H., \& McLean, E. R. (2003). The DeLone and McLean Model of Information Systems Success: A Ten-Year Update. Journal of Management Information Systems, 19(4), 9-30. https://doi.org/10.1080/07421222.2003.11045748

Fishbein, M. (1979). A theory of reasoned action: Some applications and implications. Nebraska Symposium on Motivation, 27, 65-116.

Frambach, R. T., \& Schillewaert, N. (2002). Organizational innovation adoption: a multi-level framework of determinants and opportunities for future research. Journal of Business Research, 55(2), 163-176. https://doi.org/10.1016/S0148-2963(00)00152-1

Hair JR, J. F., Sarstedt, M., Hopkins, L., \& Kuppelwieser, V. G. (2014). Partial least squares structural equation modeling (PLS-SEM): An emerging tool in business research. European Business Review, 26(2), 106-121. https://doi.org/10.1108/EBR-10-2013-0128

Henseler, J., \& Sarstedt, M. (2012). Goodness-of-fit indices for partial least squares path modeling. Computational Statistics, 28(2), 565-580. https://doi.org/10.1007/s00180-012-0317-1

Igbaria, M., Zinatelli, N., Cragg, P., \& Cavaye, A. L. M. (1997). Personal Computing Acceptance Factors in Small Firms: A Structural Equation Model. MIS Quarterly, 21(3), 279-305. https://doi.org/10.2307/249498

Lam, T., Cho, V., \& Qu, H. L. (2007). A study of hotel employee behavioral intentions towards adoption of information technology. International Journal of Hospitality Management, 26(1), 49-65. https://doi.org/10.1016/j.ijhm.2005.09.002

Lewis, W., Agarwal, R., \& Sambamurthy, V. (2003). Sources of Influence on Beliefs about Information Technology Use: An Empirical Study of Knowledge Workers. MIS Quarterly, 27(4), 657-678. Retrieved from http://www.jstor.org/stable/30036552

Stone, M. (1974). Cross-Validatory Choice and Assessment of Statistical Predictions. Journal of the Royal Statistical Society. Series B (Methodological), 36(2), 111-147. Retrieved from http://www.jstor.org/stable/2984809

Talukder, D. M. (2014). Managing Innovation Adoption: From Innovation to Implementation. Ashgate Publishing, Ltd. 


\section{Appendix}

Table 5. Constructs and measures of the variables

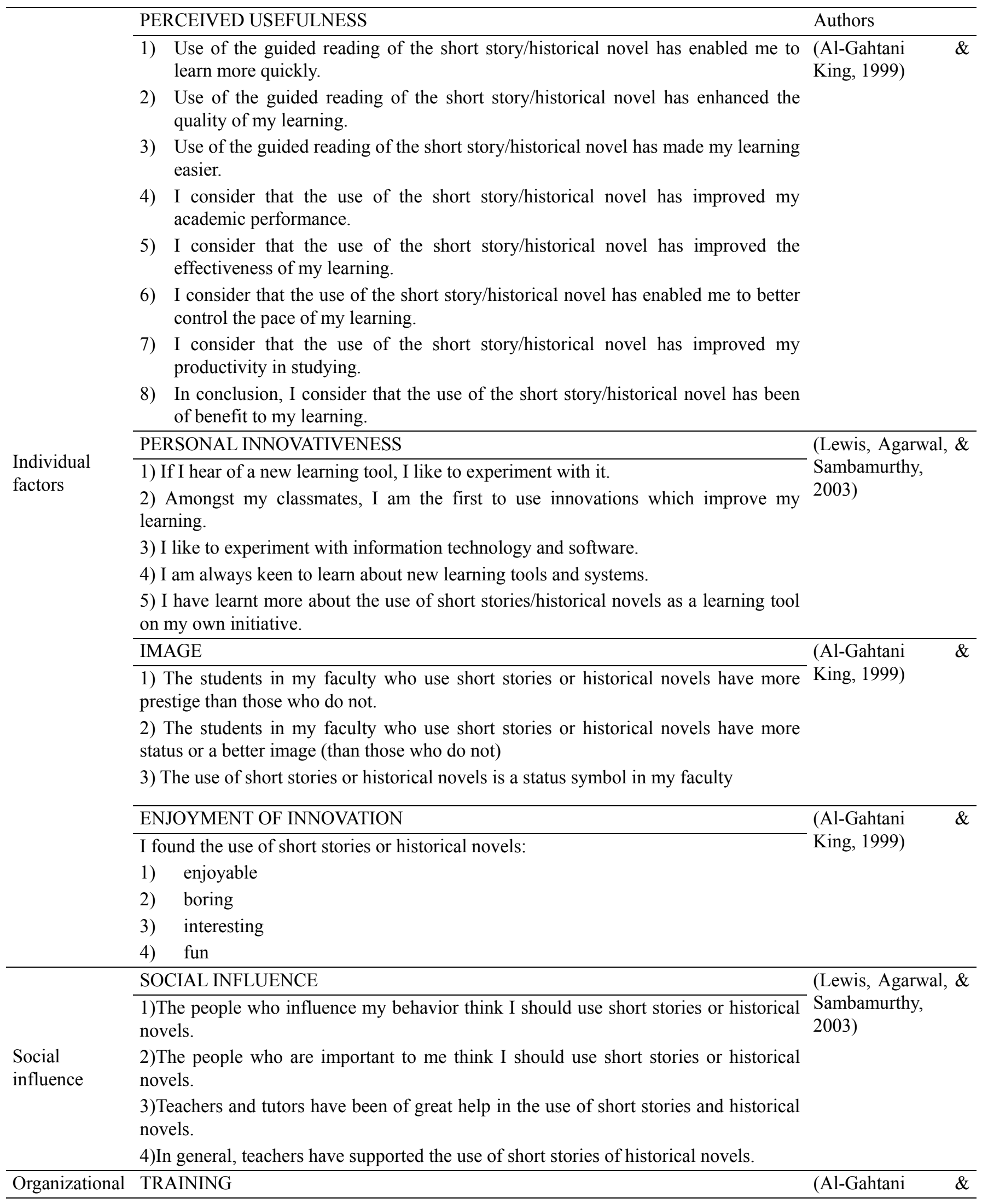


Factors

1) Your faculty has trained you in the use of the historic novel as a learning resource.

King, 1999)

2) The notions for the use of the historical novel have been clear and have helped you increase your ability to use them.

3) A specific person has given you individual support in case of difficulties with the tool.

4) A guide to the use of the historic novel has been made available to you.

MANAGERIAL SUPPORT (TEACHERS)

1) The teacher has shown focused on the benefits that may be gained by use of the historic novel in your learning.

2) The teacher has always supported and encouraged the use of the historic novel in relation to your learning or assignments.

3) The teacher has provided you with the necessary help and sources of information for the use of historical novels.

4) The teacher has provided you with good access to various sources of information when needed.

INCENTIVES (Agarwal \& Prasad,

1) The use of short stories or historical novels has led to an improvement in the 1998) effectiveness of my learning.

2) The use of short stories or historical novels has enabled me to better organize my learning.

3) The use of short stories or historical novels has been undertaken because the faculty values their use.

ATTITUDE TOWARD INNOVATION

1) I apply innovations in my learning. 2007)

Attitudes

2) I like to innovate when learning.

3) I find innovation easy.

BEHAVIOURAL INTENTION

(Lam, Cho, \& Qu,

1) I intend to use short stories and historical novels increasingly in the future for my 2007)

Behavioural learning.

intention

2) I would like to use short stories and historical novels more in the future.

3) I will probably use novels or short stories more in the future.

INDIVIDUAL ADOPTION OF INNOVATION

In relation to the total time spent using short stories or historical novels: (Batanero \& María,

1) How long have you spent using the historical novel on a scale from (a) less than half an hour, to (e) more than three hours per week.

2) Frequency of use: on average, how long have you spent per week using the

Individual adoption of innovation historical novel as class material?

of a) at least once a month or less, to e) various times a day.

3) Level of use: what has the level of use been of the historical novel in class?

a) I haven't used it at all, to e) I have used it extensively.

4) Please indicate the level of use of the historical novel in your daily activities

5) Number of texts worked on: how many texts from historical novels have you worked on simultaneously?

a) none d) more than 3 . 